\title{
The effects of flow rate and temperature on SPMD measurements of bioavailable PAHs in seawater
}

\section{Wan-Ting Chang ${ }^{a}$, Chon-Lin Lee ${ }^{\text {a,b,c,d* }}$, Peter Brimblecombe ${ }^{\mathrm{e}}$, Meng-Der Fang ${ }^{\mathrm{f}}$,}

Kuo-Tung Chang ${ }^{g}$, James T. Liu ${ }^{\text {h }}$

${ }^{a}$ Department of Marine Environment and Engineering, National Sun Yat-sen University, 80424,Kaohsiung, Taiwan, Republic of China

${ }^{b}$ Department of Public Health, College of Health Sciences, Kaohsiung Medical University, Kaohsiung, Taiwan, ROC

${ }^{c}$ Kuroshio Research Group, Asia-Pacific Ocean Research Center, National Sun Yat-sen University, 80424, Kaohsiung, Taiwan, Republic of China

${ }^{d}$ Research Center of Environmental Medicine, Kaohsiung Medical University, Kaohsiung, Taiwan, ROC

${ }^{e}$ School of Energy and Environment, City University of Hong Kong, Kowloon, HK

${ }^{f}$ Green Energy and Environment Research Laboratories, Industrial Technology Research Institute, Hsinchu, 30011, Taiwan, Republic of China

${ }^{g}$ Department of Marine Environmental Engineering, National Kaohsiung Marine University, Kaohsiung, Taiwan, Republic of China

${ }^{h}$ Department of Oceanography, National Sun Yat-sen University, Kaohsiung, Taiwan 80424, Republic of China

*Corresponding author. Department of Marine Environment and Engineering, National Sun Yat-sen University, No. 70, Lien-hai Rd. 80424, Kaohsiung, Taiwan, 
ROC. Tel.: +886 (7) 5255066; fax: +886 (7) 5255066.

E-mail address: linnohc@fac.nsysu.edu.tw (C.-L.Lee). 


\section{Abstract}

This work investigates the dependence of the sampling rate $\left(R_{s}\right)$ of semi-permeable membrane devices (SPMDs) on flow rate and temperature. The in situ $R_{s}$ values were obtained using performance reference compounds (PRCs) with weighted polynomial regression and used to estimate the bioavailable polycyclic aromatic hydrocarbon (PAH) concentrations in seawater. The in situ $R_{s}$ values did not vary with flow rate and temperature. The empirical equation of the $R_{s}$ value from the SPMDs was established. This infers that PRCs could be avoided by using an established empirical equation under similar field conditions. The sum of the bioavailable PAHs ranged from 0.281 to $0.611 \mathrm{ng} \mathrm{L}^{-1}$ on the eastern side of the Taiwan Strait and from 0.438 to $1.10 \mathrm{ng} \mathrm{\textrm {L } ^ { - 1 }}$ on the western side. Distinct sources and toxicity of these bioavailable PAHs were observed and mainly resulted from different types of energy consumption. Key words: SPMD, Sampling rate, Taiwan Strait, Bioavailability 


\section{Introduction}

The bioavailable concentration of polycyclic aromatic hydrocarbons (PAHs) in the marine environment is of paramount importance in assessing their potential to harm aquatic organisms due to their toxicity, carcinogenicity, or mutagenicity. Direct measurements of bioavailable PAHs in water samples offer the potential for effective estimates of available concentrations for uptake by marine biota.

Semipermeable membrane devices (SPMDs) have performed well in estimating the bioavailable concentrations of persistent hydrophobic chemicals in aquatic environments (Grabic et al., 2010; Jálová et al., 2013; Luellen and Shea, 2002; O'Brien et al., 2012; Y1lmaz et al., 2014) and have also fared well when compared with conventional XAD-2 resin measurements (Chang et al., 2014). Time-weighted average PAH concentrations via SPMDs $\left(C_{\mathrm{SPMD}}\right)$ in aquatic systems are estimated directly by measuring PAHs that have accumulated in the SPMD, according to Eq. (1):

$$
C_{\mathrm{SPMD}}=N / K_{s w} V_{s}\left[1-\exp \left(-R_{s} t / K_{s w} V_{s}\right)\right]
$$

where $N$ is the amount of PAHs in the SPMD (ng), $K_{s w}$ is the SPMD/water partition

coefficient $\left(\mathrm{cm}^{3} \mathrm{~cm}^{-3}\right), V_{s}$ is the SPMD volume $(\mathrm{L}), R_{s}$ is the sampling rate $\left(\mathrm{L} \mathrm{d}^{-1}\right)$, and $t$ is the sampling period in days (d). 
The sampling rate $\left(R_{s}\right)$ is key to estimating the bioavailable concentration of PAHs using SPMDs. It can be obtained from an empirical equation; however success depends on parameters such as flow rate (Booij et al., 1998; O'Brien et al., 2012; Vrana and Schuurmann, 2002), temperature (Booij et al., 2003; Huckins et al., 2002), bio-fouling (Booij et al., 2006; Huckins et al., 2002; Richardson et al., 2005), and the geometry of the mounting cages. Several researchers have suggested the use of PRCs, such as perdeuterated PAHs, to obtain more reliable in situ sampling rates (Booij et al., 1998; Booij and Smedes, 2010; Ellis et al., 1995; Huckins et al., 2006). Furthermore, multiple PRCs tuned with cubic polynomial regressions have been used to estimate in situ sampling rates under field conditions (Chang et al., 2014). The PRCs can aid in calculating $R_{s}$ values, but PRCs added to the SPMD render the collected samples unsuitable for bioassays due to their toxicity (Couillard et al., 2005; Jálová et al., 2013), although the toxicity of PRC standards used in the environment is extremely low due to their substantial dilution. It is therefore preferable to limit the use of PRCs for routine monitoring.

In the literature, the sampling rate determined from a flow rate of $30 \mathrm{~cm} \mathrm{~s}^{-1}$ was found to be about three times higher than that of $0.03 \mathrm{~cm} \mathrm{~s}^{-1}$ (Booij et al., 1998). Regarding the effect of temperature, the sampling rate at $30^{\circ} \mathrm{C}$ was found to be three times larger than that at $2^{\circ} \mathrm{C}$ (Booij et al., 2003). Understanding the dependence of $R_{s}$ 
on flow rate and temperature could help eliminate or reduce the need for PRCs. It should be noted that $R_{s}$ values from the above literature were based on laboratory measurements. Therefore simultaneous measurements of in situ flow rate and temperature with SPMD deployment in the field should be carried out to better understand the dependence of the sampling rate within those parameters.

Our objectives are to establish the empirical equation for $R_{s}$, and to obtain the in situ $R_{s}$ values using PRCs and assess their dependence on the in situ flow rates and temperatures. Additionally, the work aims to measure the bioavailable PAH concentrations from seawater samples across the Taiwan Strait and to identify their possible sources and toxicity. 


\section{Materials and methods}

\subsection{Chemicals}

Organic solvents used in this study were SupraSolv grade purchased from Merck Co., Germany. Aluminum oxide was baked at $550^{\circ} \mathrm{C}$ before use. Perdeuterated standards including phenanthrene-d10, acenaphthene-d10, and benzo[a]anthracene-d12 were purchased from Supelco, USA. Perylene-d12, fluorene-d10, fluoranthene-d10, and benzo[a]pyrene-d12 were purchased from Chem Service, USA. Benzo[g,h,i]perylene-d12, anthracene-d10, benzo[K]fluoranthen-d12, pyrene-d10, and indeno[1,2,3-CD]pyrene-d12 were purchased from Cambridge Isotope Laboratories, USA. PAH calibration standards were purchased from AccuStandard, USA.

The SPMDs and stainless steel mesh cages were purchased from Environmental Sampling Technologies Inc. (EST), St. Joseph, MO, USA. Standard size SPMDs were constructed from low-density polyethylene tubes $(91.4 \times 2.5 \mathrm{~cm}, 70$ to $95 \mu \mathrm{m}$ wall thickness) and contained $1 \mathrm{~mL}(0.91 \mathrm{~g})$ of triolein. Each SPMD in the experiment was spiked with $1 \mu \mathrm{g} \quad$ acenaphthene-d10, anthracene-d10, pyrene-d10, benzo[K]fluoranthen-d12, and indeno[1,2,3-CD]pyrene-d12 as a PRC. 


\subsection{Sampling}

The sampling sites (T1, T2, T3, C1 and C2) are shown in Fig. 1. Deployment information and seawater parameters for the sampling sites are listed in Table S1, including the sampling period, seawater depth, flow rates and seawater temperatures. The SPMDs and stainless steel mesh cages from EST were deployed with a sediment trap mooring at stations $\mathrm{C} 1$ and $\mathrm{C} 2$, with a buoy at stations T2 (outer Mai Liao harbor) and T3 (inner Mai Liao harbor) stations, and with a platform hung from the vessel Ocean Researcher III (Fig. S2, cruise ORIII-1623) at T1 station. Two standard SPMDs with PRCs were suspended in a stainless steel mesh cage at each sampling site. A Nortek Aquadopp profiler and temperature logger were placed close to the SPMD samplers to determine the in situ flow rate and temperature. The SPMDs were wrapped individually in a stainless steel box after collection and kept frozen $\left(-20^{\circ} \mathrm{C}\right)$. 


\subsection{Analysis and sample processing}

Fouling was removed from the SPMD with Kimwipes tissue before the extraction procedure. The SPMD was then rinsed with Milli-Q water and soaked in $150 \mathrm{~mL}$ of n-hexane with added surrogate standards in a pre-cleaned amber glass bottle for $18 \mathrm{~h}$ at $18^{\circ} \mathrm{C}$ in the dark. Extraction was repeated for an additional $6 \mathrm{~h}$ with fresh solvent. These two fractions were combined and concentrated to about $1.5 \mathrm{~mL}$ using rotary evaporation. Concentrated extracts were cleaned up using gel permeation chromatography (GPC) to remove polyethylene and remaining co-dialyzed lipids. The GPC system consisted of a HPLC (L-2130, Hitachi, Japan) with PL EnviroPrep organic GPC columns $(19 \times 300 \mathrm{~mm}$, Varian, USA) and a UV detector (L-4200, Hitachi, Japan) at $254 \mathrm{~nm}$. The mobile phase was dichloromethane, with a flow rate of $8 \mathrm{~mL} \mathrm{~min}^{-1}$. The extract fractionated from the GPC system was eluted with petroleum ether through a column packed with aluminum oxide to remove the polar interferences. The extract was evaporated under a gentle stream of nitrogen to $0.5 \mathrm{~mL}$. 


\subsection{Quantification and instrumental analysis}

Three perdeuterated PAHs (fluorene-d10, fluoranthene-d10, and pyrene-d12) were added as surrogates to each sample before extraction to monitor the performance of the overall analytical procedure. The average recovery for fluorene-d10, fluoranthene-d10, and pyrene-d12 was $84 \pm 36 \%, 82 \pm 20 \%$, and $70 \pm 17 \%$ for the SPMD samples. The PAH concentrations measured in this study were corrected using the surrogate recovery. For quantification, each extract was spiked with phenanthrene-d10, benzo[a]anthracene-d12, benzo[a]pyrene-d12, and benzo[g,h,i]perylene-d12 as the internal standards and analyzed on an Agilent 6890 gas chromatograph with an Agilent 5973N mass selective detector (GC/MSD) operating in the selected ion-monitoring mode.

Laboratory and field blanks were incorporated in the analysis to quantify possible contamination due to collection, transport, and extraction. The mean detection limits (MDLs) were derived from the blanks and defined as the mean concentrations plus three times the standard deviation in the blank for each PAH compound. For the 22 PAH compounds, the MDLs ranged from 0.071 to $11.6 \mathrm{ng} / \mathrm{SPMD}$ for the SPMD samples.

Data processing was performed on Pearson and Kendall's correlation coefficients 
using Statistical Product and Service Solutions (SPSS) and ZunZun (ZunZun.com, 2014). The accuracy of the empirical equation was assessed using two measures: root mean squared error (RMSE) in Eq. (2) and mean absolute error (MAE) in Eq. (3)

$$
\begin{aligned}
& \text { RMSE }=\sqrt{\frac{\sum_{n=1}^{N}\left(\log R_{S \text { observed }}-\log R_{\text {s predicted }}\right)^{2}}{N}} \\
& \text { MAE }=\frac{\sum_{n=1}^{N}\left|\log R_{S \text { observed }}-\log R_{\text {s predicted }}\right|}{N}
\end{aligned}
$$

where $N$ is the number of variables, $\log \left(R_{s}\right.$ observed $)$ is the $\log R_{s}$ from PRC in this study, and $\log \left(R_{s}\right.$ predicted $)$ is the output $\log \left(R_{s}\right)$ from the empirical equation. When RMSE and MAE values are smaller and closer to zero, it indicates that these measures represent better agreement with the empirical equation.

The toxic equivalent factor (TEF) was used to estimate the toxic equivalents (TEQs) and assess the PAH toxicity to aquatic organisms (Nisbet and LaGoy, 1992). 


\section{Results and discussion}

\subsection{Estimated sampling rate using PRCs}

The exchange kinetics that characterizes release and uptake rates was established using the PRC exchange from the SPMDs. Five PRCs were added to each SPMD before exposure to examine the in situ exchange processes. The PRCs allow us to estimate the in situ release rate constant $k_{e-\text { PRC }}$ (Booij et al., 2003; Huckins et al., 2002). Huckins et al. (2006) provided a PRC-based methodology for calibrating field sampling rates. The PRC dissipation rate constant $\left(k_{e-\mathrm{PRC}}\right)$ was estimated according to the first-order exchange process in Eq. (4) (Huckins et al., 2006):

$$
k_{e-\mathrm{PRC}}=-\ln \left(N / N_{0}\right) / t
$$

where $t$ is the exposure time (days) of the deployment, $N$ is the amount (ng) of PRC present in the SPMD after dissipation, and $N_{0}$ is the initial amount (ng) at $t=0$. The recovery rates $\left(N / N_{0}\right)$ of all PRCs (Acen-d10, An-d10, Py-d10, BkFa-d12 and INP-d12) are ranged: $0.08-13.4 \%, \quad 4.03-39.5 \%, \quad 34.5-69.6 \%, \quad 54.8-88.9$ and 81.4-97.6\%, respectively (Table 1). The $k_{e-\mathrm{PRC}}$ for sampling sites is shown in Table 1 as determined using Eq. (4).

The PRC sampling rate was estimated from Eq. (5):

$$
R_{s-\mathrm{PRC}}=V_{\mathrm{SPMD}} k_{e-\mathrm{PRC}} K_{s w}
$$

where $V_{\text {SPMD }}$ is the total volume of the SPMD (L) and $K_{s w}$ the SPMD-water partition 
coefficients, which are obtained from a quadratic regression (Huckins et al., 2006;

Huckins et al., 2002) as in Eq. (6) for PAH compounds:

$\log K_{s w}=-0.1618 \log K_{o w}{ }^{2}+2.321 \log K_{o w}-2.61 \quad 2<\log K_{o w}<7$

The $R_{s-\text { PRC }}$ values calculated using $K_{s w}$ from Eq. (6) are shown in Table 1 . The weighted polynomial fit was performed using ZunZun (ZunZun.com, 2014) which allowed the individual $R_{S}$ values for PRC to be weighted according to the percentage of PRC recovery $\left(N / N_{0}\right)$ (Chang et al., 2014). The $R_{s}$ values have been determined for the samples collected from the seawater using the five PRCs (Table S2) and are shown in Fig. 2. Although the shapes of the polynomials from the six sites are different, $\log \left(R_{s}\right)$ revealed their maxima to be around a $\log \left(K_{o w}\right)$ value of 6 . This shows that different ambient conditions lead to $R_{s}$ values of quite different magnitude and shape. The regression curves we used were thus tuned to conditions in the seawater, so that the shape and magnitude are likely the best representation of our sampling rates. 


\subsection{Effect of environmental parameters on sampling rate}

Huckins et al. (2006) used a cubic polynomial to represent the relationship

between $\log \left(R_{s}\right)$ and $\log \left(K_{o w}\right)$. $\log \left(R_{s i, \mathrm{j}}\right)$ can be denoted with the

compound-specific effect of a particular compound $\log \left(K_{o w, \mathrm{i}}\right)$ and the

exposure-specific effect of exposure $\left(a_{0, \mathrm{j}}\right)$ and calculated using Eq. (7) (Huckins et al., 2006):

$\log R_{s \mathrm{i}, \mathrm{j}}=0.0130 \log K_{o w, \mathrm{i}}{ }^{3}-0.3173 \log K_{o w, \mathrm{i}}{ }^{2}+0.244 \log K_{o w, \mathrm{i}}+a_{0, \mathrm{j}}$

where the $a_{0, \mathrm{j}}$ is the intercept that is observed for calibration of the exposure

experiment (j), so that the log-transformed exposure-specific sampling rate can be expressed as $\log \left(R_{s, \mathrm{j}}\right)$ in an exposure $(\mathrm{j}) . \log \left(R_{s, \mathrm{j}}\right)$ values were calculated from the $R_{s-\mathrm{PRC}}$ values and are shown in Table 1 . These PAH sampling rates are exposure-specific, and depend on environmental parameters such as the flow rate and the seawater temperature. The environmental parameters of the average flow rates from all stations in this study ranged from 5.3 to $63.1 \mathrm{~cm} \mathrm{~s}^{-1}$ and the average seawater temperatures ranged from 9.8 to $28.7^{\circ} \mathrm{C}$ as shown in Table $\mathrm{S} 1$.

$\log \left(R_{s, \mathrm{j}}\right)$ values were estimated from the dissipation of PRCs in the SPMDs as a function of flow rate and temperature (Fig. 3). The highest variation of $\log \left(R_{s, \mathrm{j}}\right)$ values was observed at $\mathrm{T} 1$ station, possibly because the highest flow rate and the highest temperature of any of the sampling sites were found here. Furthermore, the 
SPMDs at T1 station were hung from the ORIII during the cruise. Thus the structure of the flow at $\mathrm{T} 1$ station was quite different to that at other stations, and the high turbulence caused the $\log \left(R_{s, \mathrm{j}}\right)$ values to be highly variable here.

Linear correlation analysis using the $\log \left(R_{s, \mathrm{j}}\right)$ from five stations (T1 station excluded) where the flow rates ranged from 5.3 to $40.5 \mathrm{~cm} \mathrm{~s}^{-1}$ and the temperatures ranged from 9.8 to $25.2^{\circ} \mathrm{C}$ was fitted as the solid line in Fig. 3. $\log \left(R_{s, j}\right)$ did not show a statistically significant variation with either flow rate $(r=0.070, p=0.627)$ or temperature $(r=-0.214, p=0.136)$. It should be noted that similar results were also observed for both $R_{s, \mathrm{j}}$ and $R_{s}$, showing no significant correlation for any of the PRCs with either flow rate or temperature (Table S3). This is in contrast to what has been reported in the literature, which suggests that in the laboratory these parameters have significant effects on sampling rates when increasing the flow rate from 0.03 to $30 \mathrm{~cm}$ $\mathrm{s}^{-1}$ (Booij et al., 1998) and the temperature from 2 to $30^{\circ} \mathrm{C}$ (Booij et al., 2003). It may be that measurements made in the laboratory yield responses that are quite different to those made in the field, which might be explained by the cage effect or the different ranges studied. Previous work has shown the geometry of the mounting cage to affect the $R_{S}$ value (Huckins et al., 2006). In addition, the flow rates measured outside the cages were found to be about two times higher than those measured inside the cages (Louch et al., 2003). The structure of the flow inside the cage was generally unknown, 
though the flow rates of sampling sites were measured. The fact that the sampling rates do not vary with flow rate and temperature suggests that PRCs could be avoided by establishing a field empirical equation, as described in the next section, if the cage geometry and flow conditions were similar to those in our study. This could benefit routine deployment in monitoring the aquatic environment. 


\subsection{Field empirical equation for $R_{s}$}

The weighted polynomial fit of $\log \left(R_{s-\mathrm{PRC}}\right)$ with $\log \left(K_{o w}\right)$ gives Eq. (8). It is weighted according to the percentage of PRC recovery from five seawater stations (excluding the cruise station T1).

$$
\log R_{s}=-0.141 \log K_{o w}{ }^{3}+2.10 \log K_{o w}{ }^{2}-10.0 \log K_{o w}+16.4
$$

$$
5.3<\text { flow rate }<40.5 \mathrm{~cm} \mathrm{~s}^{-1} \quad 9.8<\text { temperature }<25.2^{\circ} \mathrm{C}
$$

This field empirical equation Eq. (8) can potentially be used to establish, without PRCs, the PAHs $R_{s}$ values under environmental conditions in seawater using SPMDs and cage devices purchased from EST.

The data obtained from this field empirical equation were plotted against those from experiments for comparison (Fig. 4). The slopes of $\log \left(R_{s}\right)$ values with $\log \left(R_{S}\right)$ values from the field empirical equation are close to one (Fig. 4). The accuracy of the predictions was checked by calculating the root mean squared error (RMSE) and mean of absolute error (MAE) as shown in Table 2. Both were quite small and close to zero, suggesting that the field empirical equation is accurate. 


\subsection{The bioavailable $P A H$ concentrations $C_{\mathrm{SPMD}}$}

The sums of the 22 bioavailable PAH concentrations in seawater estimated from

SPMDs $\left(C_{\mathrm{SPMD}}\right)$ were $0.611,0.281$, and $0.518 \mathrm{ng} \mathrm{L}^{-1}$ for the $\mathrm{T} 1$, T2, and $\mathrm{T} 3$ stations on the eastern side of the Taiwan Strait (Fig. 5), respectively; the sums were 0.438, 1.10 and $1.02 \mathrm{ng} \mathrm{L}^{-1}$ for the $\mathrm{C} 1, \mathrm{C} 2-\mathrm{A}$ and $\mathrm{C} 2-\mathrm{B}$ stations, respectively on the western side of the Taiwan Strait, as shown in Fig. 5.This is the first time SPMDs have been used to determine the bioavailable PAH concentrations in the Taiwan Strait. The concentrations in this study were comparable with measurements made using SPMDs in the Mediterranean Sea (Marrucci et al., 2013) and measurements made from seawater samples collected from the Black Sea and the Mediterranean Sea (Berrojalbiz et al., 2011), as displayed in Table S4.

The bioavailable PAH compositional pattern on the eastern side of the Taiwan Strait was dominated by phenanthrene (21.5-46.8\%), followed by fluorene $(4.85-50.3 \%)$ and pyrene $(6.5-10.2 \%)$. These compounds were probably related to volatilization or spillage of petroleum-related products (Huang et al., 2012; Lai et al., 2011). The $C_{\text {SPMD }}$ compositional pattern on the western side of the Taiwan Strait was dominated by fluoranthene $(15.2-32.1 \%)$, followed by pyrene $(10.6-26.8 \%)$ and phenanthrene (7.27-14.5\%). Larsen and Baker (2003) identified these as the main PAH compounds emitted from coal combustion (Larsen and Baker, 2003). The 
dominant PAHs were quite different on the eastern (3rings PAHs) and the western (4rings PAHs) sides of the Taiwan Strait. This could be explained by different types of energy consumption in the two areas. The ratio of total coal consumption divided by petroleum consumption in China was about three times higher than that in Taiwan, as shown in Fig. S1 (EIA, 2014).

The bioavailable PAH TEQ is the sum of the 16 toxic equivalents, normalized to benzo[a]pyrene, from PAHs in the sample. The total bioavailable PAH TEQs from the SPMDs were $0.015,0.020$ and $0.005 \mathrm{ng} \mathrm{L}^{-1}$ for $\mathrm{T} 1, \mathrm{~T} 2$ and $\mathrm{T} 3$ stations on the eastern side of the Taiwan Strait and 0.057, 0.067 and $0.041 \mathrm{ng} \mathrm{L}^{-1}$ for C1, C2-A and C2-B stations on the western side of the Taiwan Strait. The bioavailable toxicity of seawater on the western side of the Taiwan Strait $\left(0.005-0.02 \mathrm{ng} \mathrm{L}^{-1}\right)$ is about two times greater

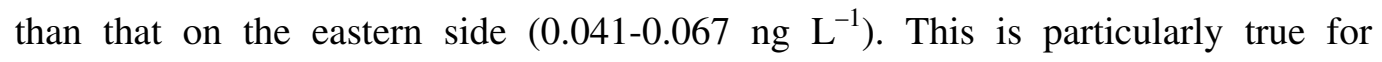
benzo(a)pyrene $(\mathrm{TEF}=1)$, which has a much higher concentration on the western side than on the eastern side (Fig. 5). 


\subsection{Principal component analysis}

Identifying PAH sources using specific PAHs seemed too arbitrary, so we used the concentration of the 22 measured PAHs to represent the major sources in the Taiwan Strait. PCA was used in exploratory analysis to suggest possible sources of the PAHs. Four principal components were extracted and each accounted for more than $10 \%(38.5 \%, 27.9 \% 19.5 \%$, and $12.9 \%$, Table 3$)$, which explained $98.8 \%$ of the total variance. Those factors corresponding to correlation matrix eigenvalues greater than one are considered meaningful and are listed in Table 3.

PC1 has significant positive loadings for coronene, chrysene+triphenylene, dibenz[a,h]anthracene, perylene, benzo[k]fluoranthene, benzo[g,h,i]perylene, benzo[e]pyrene, benzo[a]pyrene, and retene. This could be related to incomplete combustion of organic matter such as coal or crude oils (Benner et al., 1989; Budzinski et al., 1997).

PC2 shows positive loadings of benz[a]anthracene and benzo[b]fluorine, which could be related to incomplete combustion of organic matter such as coal or crude oils

(Benner et al., 1989; Budzinski et al., 1997). Anthracene, phenanthrene, and dibenzothiopheneare were associated with significant negative loading in PC2, and likely represent volatilization or spillage of petroleum-related products (Huang et al., 2012; Lai et al., 2011; Larsen and Baker, 2003). 
PC3 shows positive loadings for pyrene, fluoranthene, and benzo[a]fluorine probably representing coal burning (Fang et al., 2007; Larsen and Baker, 2003), but the negative loadings for fluorene and acenaphthene represent volatilization or petroleum-related product spills (Huang et al., 2012; Lai et al., 2011; Larsen and Baker, 2003). Consequently, the bioavailable PAH compositional pattern in the Taiwan Strait can be categorized into three predominant sources: incomplete combustion of organic matter such as crude oils, coal burning, and volatilization or spillage of petroleum-related products.

The PCA component scores of PC2 and PC3 are shown in Fig. 6. The bioavailable PAHs in the Taiwan Strait were separated into two groups: one from the eastern side of the Taiwan Strait (Group T) and the other from the western side of the Taiwan Strait (Group C). The PAHs in Group $\mathrm{T}$ were mainly derived from volatilization or spills of petroleum-related products, while those in Group C seemed more dependent on incomplete combustion of organic matter and coal burning. 


\section{Conclusions}

The $R_{s}$ values in seawater from different stations were obtained using a weighted polynomial fit with the PRCs. The in situ $R_{s}$ values were found to be unrelated to the

flow rate (ranged 5.3 to $40.5 \mathrm{~cm} \mathrm{~s}^{-1}$ ) and temperature (ranged 9.8 to $25.2{ }^{\circ} \mathrm{C}$ ) in this study. A field empirical equation was established and used to predict the $R_{s}$ values in seawater without PRCs. Such samples collected by SPMD and not contaminated by toxic PRCs are suitable for further research, such as bioassay. Further, the fact that PRCs could be excluded using the approach proposed in this study benefits routine monitoring of the aquatic environment. Finally, distinct compositional patterns were found across the Taiwan Strait, indicating different dominant sources: the volatilization or spillage of petroleum-related products on the Taiwan side of the strait, and coal combustion on the Chinese side. 


\section{Acknowledgements}

The authors acknowledge financial support from the Ministry of Science and Technology (NSC 101-2611-M-110-012), the Ministry of Education of Taiwan, ROC (DOE 02C030203) and the Research Center of Environmental Medicine, KMU (KMU-TP103A27). Thanks also to all crew members of the ocean research vessels

ORI、ORII、ORIII and OR5 for their generous support and excellent assistance in the sampling campaigns. We express our gratitude to Yun-Jie Huang, Jay Lee, Rick Yang, Ray Hsu, Xiaoqin Du, Jason Cheng, and Huan-Meng Chang for their participation in this research. We also wish to thank Teng Hung construction for their diving sampling assistance. 
Benner, B.A., Gordon, G.E., Wise, S.A., 1989. Mobil sources of atmospheric polycyclic aromatic-hydrocarbons - a roadway tunnel study. Environ. Sci. Technol. 23, 1269-1278.

Berrojalbiz, N., Dachs, J., Ojeda, M.J., Valle, M.C., Castro-Jimenez, J., Wollgast, J., Ghiani, M., Hanke, G., Zaldivar, J.M., 2011. Biogeochemical and physical controls on concentrations of polycyclic aromatic hydrocarbons in water and plankton of the Mediterranean and Black Seas. Global Biogeochemical Cycles 25.

Booij, K., Hofmans, H.E., Fischer, C.V., Van Weerlee, E.M., 2003. Temperature-dependent uptake rates of nonpolar organic compounds by semipermeable membrane devices and low-density polyethylene membranes. Environ. Sci. Technol. 37, 361-366.

Booij, K., Sleiderink, H.M., Smedes, F., 1998. Calibrating the uptake kinetics of semipermeable membrane devices using exposure standards. Environ. Toxicol. Chem. 17, 1236-1245.

Booij, K., Smedes, F., 2010. An improved method for estimating in situ sampling rates of nonpolar passive samplers. Environ. Sci. Technol. 44, 6789-6794.

Booij, K., van Bommel, R., Mets, A., Dekker, R., 2006. Little effect of excessive biofouling on the uptake of organic contaminants by semipermeable membrane devices. Chemosphere 65, 2485-2492.

Budzinski, H., Jones, I., Bellocq, J., Pierard, C., Garrigues, P., 1997. Evaluation of sediment contamination by polycyclic aromatic hydrocarbons in the Gironde estuary. Mar. Chem. 58, 85-97.

Chang, W.-T., Fang, M.-D., Lee, C.-L., Brimblecombe, P., 2014. Measuring bioavailable $\mathrm{PAHs}$ in estuarine water using semipermeable membrane devices with performance reference compounds. Mar. Pollut. Bull. 89, 376-383.

Couillard, C.M., Lee, K., Legare, B., King, T.L., 2005. Effect of dispersant on the composition of the water-accommodated fraction of crude oil and its toxicity to larval marine fish. Environ. Toxicol. Chem. 24, 1496-1504.

EIA, 2014. U.S. Energy Information Administration. Available: http://www.eia.gov/.

Ellis, G.S., Huckins, J.N., Rostad, C.E., Schmitt, C.J., Petty, J.D., Maccarthy, P., 1995. Evaluation lipid-containing semipermeable-membrane devices for monitoring organochlorine contaminants in the upper Mississippi river. Environ. Toxicol. Chem. 14, 1875-1884.

Fang, M.D., Hsieh, P.C., Ko, F.C., Baker, J.E., Lee, C.L., 2007. Sources and distribution of polycyclic aromatic hydrocarbons in the sediments of Kaoping river and submarine canyon system, Taiwan. Mar. Pollut. Bull. 54, 1179-1189. 
Grabic, R., Jurcikova, J., Tomsejova, S., Ocelka, T., Halirova, J., Hypr, D., Kodes, V., 2010. Passive sampling methods for monitoring endocrine disruptors in the Svratka and Svitava rivers in the Czech Republic. Environ. Toxicol. Chem. 29, 550-555.

Huang, H.C., Lee, C.L., Lai, C.H., Fang, M.D., Lai, I.C., 2012. Transboundary movement of polycyclic aromatic hydrocarbons (PAHs) in the Kuroshio Sphere of the western Pacific Ocean. Atmos. Environ. 54, 470-479.

Huckins, J.N., Petty, J.D., Booij, K., 2006. Monitors of organic chemicals in the environment : semipermeable membrane devices. Springer, New York.

Huckins, J.N., Petty, J.D., Lebo, J.A., Almeida, F.V., Booij, K., Alvarez, D.A., Cranor, W.L., Clark, R.C., Mogensen, B.B., 2002. Development of the Permeability/Performance Reference Compound Approach for In Situ Calibration of Semipermeable Membrane Devices. Environ. Sci. Technol. 36, 85-91.

Jálová, V., Jarošová, B., Bláha, L., Giesy, J.P., Ocelka, T., Grabic, R., Jurčíková, J., Vrana, B., Hilscherová, K., 2013. Estrogen-, androgen- and aryl hydrocarbon receptor mediated activities in passive and composite samples from municipal waste and surface waters. Environment International 59, 372-383.

Lai, I.C., Lee, C.L., Zeng, K.Y., Huang, H.C., 2011. Seasonal variation of atmospheric polycyclic aromatic hydrocarbons along the Kaohsiung coast. J. Environ. Manage. 92, 2029-2037.

Larsen, R.K., Baker, J.E., 2003. Source apportionment of polycyclic aromatic hydrocarbons in the urban atmosphere: A comparison of three methods. Environ. Sci. Technol. 37, 1873-1881.

Louch, J., Allen, G., Erickson, C., Wilson, G., Schmedding, D., 2003. Interpreting Results from Field Deployments of Semipermeable Membrane Devices. Environ. Sci. Technol. 37, 1202-1207.

Luellen, D.R., Shea, D., 2002. Calibration and field verification of semipermeable membrane devices for measuring polycyclic aromatic hydrocarbons in water. Environ. Sci. Technol. 36, 1791-1797.

Marrucci, A., Marras, B., Campisi, S.S., Schintu, M., 2013. Using SPMDs to monitor the seawater concentrations of PAHs and PCBs in marine protected areas (Western Mediterranean). Mar. Pollut. Bull. 75, 69-75.

Nisbet, I.C.T., LaGoy, P.K., 1992. Toxic equivalency factors (TEFs) for polycyclic aromatic hydrocarbons (PAHs). Regulatory Toxicology and Pharmacology 16, 290-300.

O'Brien, D., Komarova, T., Mueller, J.F., 2012. Determination of deployment specific chemical uptake rates for SPMD and PDMS using a passive flow monitor. 
Mar. Pollut. Bull. 64, 1005-1011.

Richardson, B.J., Tse, E.S.C., De Luca-Abbott, S.B., Martin, M., Lam, P.K.S., 2005. Uptake and depuration of PAHs and chlorinated pesticides by semi-permeable membrane devices (SPMDs) and green-lipped mussels (Perna viridis). Mar. Pollut. Bull. 51, 975-993.

Vrana, B., Schuurmann, G., 2002. Calibrating the uptake kinetics of semipermeable membrane devices in water: Impact of hydrodynamics. Environ. Sci. Technol. 36, 290-296.

Yılmaz, A., Karacık, B., Henkelmann, B., Pfister, G., Schramm, K.W., Yakan, S.D., Barlas, B., Okay, O.S., 2014. Use of passive samplers in pollution monitoring: A numerical approach for marinas. Environment International 73, 85-93.

ZunZun.com, 2014. Online curve and surface fitting. Available: http://zunzun.com 


\section{Figure Captions}

Figure 1 Sampling sites in the Taiwan Strait.

Figure 2 Log sampling rate $\log \left(R_{s}\right)$ as a function of $\log \left(K_{o w}\right)$ for PAHs. Circles: $\log$ $\left(R_{s}\right)$ from C1 station; Triangles: $\log \left(R_{S}\right)$ from C2-A station; Crosses: $\log \left(R_{S}\right)$ from C2-B station; Squares: $\log \left(R_{s}\right)$ from T1 station; Diamonds: $\log \left(R_{s}\right)$ from T2 station; Plus Signs: $\log \left(R_{s}\right)$ from T3 station. (Fitting equation: Bold Dotted Line: $\log R_{s}=$ $-0.074 \log K_{o w}{ }^{3}+0.995 \log K_{o w}{ }^{2}-4.18 \log K_{o w}+6.46$; Bold Solid Line: $\log R_{s}=$ $-0.108 \log K_{o w}{ }^{3}+1.56 \log K_{o w}{ }^{2}-7.25 \log K_{o w}+12.1$; Bold Dashed Line: $\log R_{s}=$ $-0.217 \log K_{o w}{ }^{3}+3.30 \log {K_{o w}}^{2}-16.2 \log K_{o w}+26.7$; Fine Dotted Line: $\log R_{s}=$ $-0.384 \log K_{o w}{ }^{3}+6.08 \log K_{o w}{ }^{2}-31.3 \log K_{o w}+53.9 ;$ Fine Solid Line: $\log R_{s}=$ $-0.083 \log K_{o w}{ }^{3}+1.20 \log K_{o w}{ }^{2}-5.40 \log K_{o w}+8.64$; Fine Dashed Line: $\log R_{S}=$ $\left.-0.112 \log K_{o w}{ }^{3}+1.61 \log K_{o w}{ }^{2}-7.11 \log K_{o w}+10.6\right)$

Figure $3 \log \left(R_{s, \mathrm{j}}\right)$ distribution with (a) temperatures and (b) flow rates. Bold Dashed Line: Linear regressions using $\log \left(R_{s, \mathrm{j}}\right)$ with temperatures and flow rates from all stations. Bold Solid Line: linear regressions using $\log \left(R_{s, \mathrm{j}}\right)$ with temperatures and flow rates from five stations without $\mathrm{T} 1$ station. 
Figure $4 \log \left(R_{s}\right)$ from PRCs in this study with $\log \left(R_{s}\right)$ values from empirical equation. Circles: C1 station; Triangles: C2-A station; Crosses: C2-B station; Diamonds: T2 station; Plus Signs: T3 station.

Figure 5 Bioavailable PAH concentrations from SPMDs $\left(C_{\mathrm{SPMD}}\right)$.

Figure 6 Scores plot of the two principal components (PC2 and PC3) from the Taiwan Strait. Dashed Line encloses the group on the eastern side of the Taiwan Strait; Solid Line encloses the group on the western side of the Taiwan Strait. 


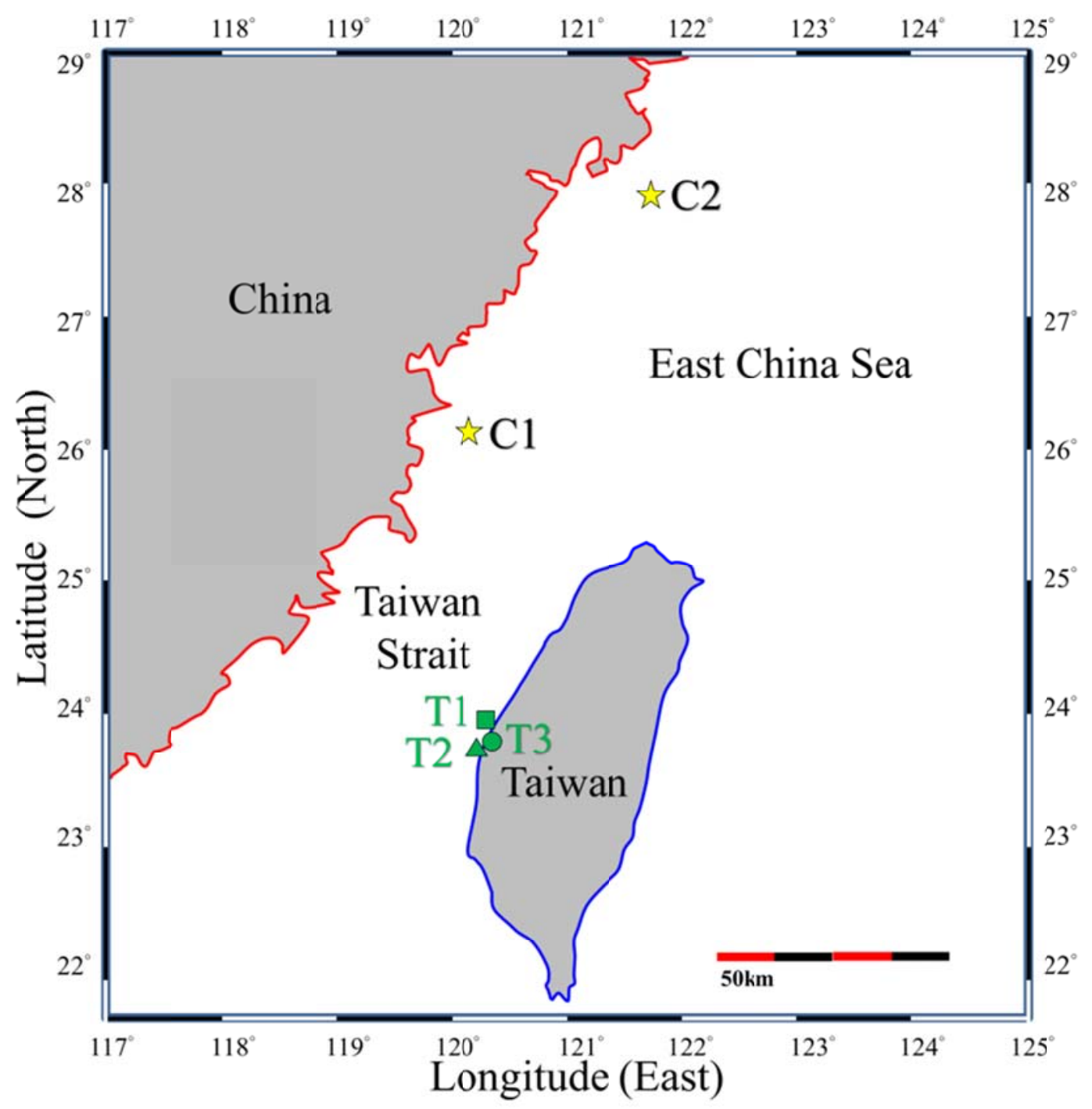

Figure 1 Sampling sites in the Taiwan Strait. 


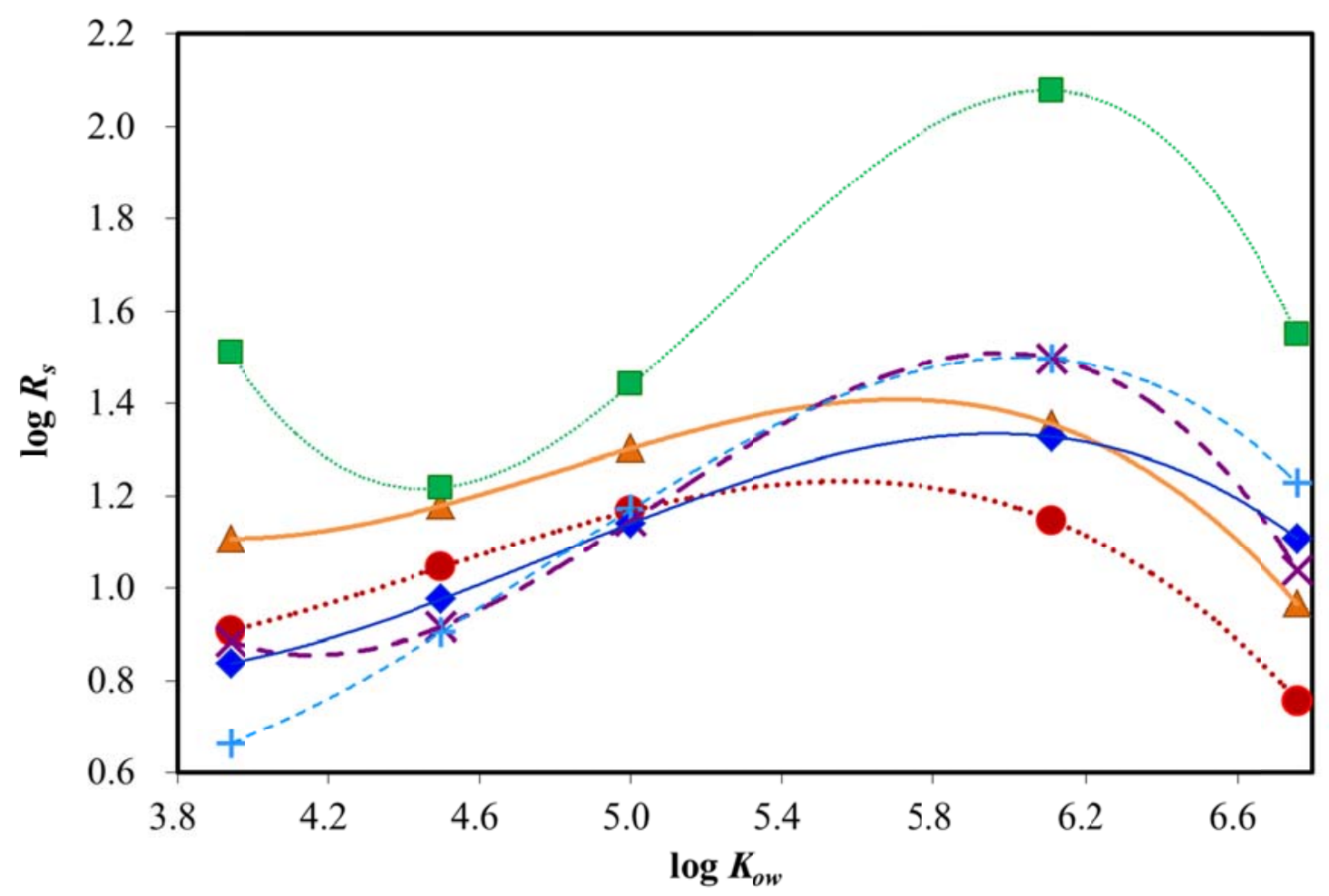

Figure 2 Log sampling rate $\log \left(R_{s}\right)$ as a function of $\log \left(K_{\text {ow }}\right)$ for PAHs. Circles: $\log$ $\left(R_{S}\right)$ from C1 station; Triangles: $\log \left(R_{S}\right)$ from C2-A station; Crosses: log $\left(R_{S}\right)$ from C2-B station; Squares: $\log \left(R_{s}\right)$ from T1 station; Diamonds: $\log \left(R_{s}\right)$ from T2 station; Plus Signs: $\log \left(R_{s}\right)$ from T3 station. (Fitting equation: Bold Dotted Line: $\log R_{s}=$ $-0.074 \log K_{o w}{ }^{3}+0.995 \log K_{o w}{ }^{2}-4.18 \log K_{o w}+6.46$; Bold Solid Line: $\log R_{s}=$ $-0.108 \log K_{o w}{ }^{3}+1.56 \log K_{o w}{ }^{2}-7.25 \log K_{o w}+12.1$; Bold Dashed Line: $\log R_{s}=$ $-0.217 \log K_{o w}{ }^{3}+3.30 \log K_{o w}{ }^{2}-16.2 \log K_{o w}+26.7$; Fine Dotted Line: $\log R_{s}=$ $-0.384 \log K_{o w}{ }^{3}+6.08 \log K_{o w}{ }^{2}-31.3 \log K_{o w}+53.9 ;$ Fine Solid Line: $\log R_{s}=-0.083$ $\log K_{o w}{ }^{3}+1.20 \log K_{o w}{ }^{2}-5.40 \log K_{o w}+8.64$; Fine Dashed Line: $\log R_{s}=-0.112 \log$ $\left.K_{o w}{ }^{3}+1.61 \log K_{o w}{ }^{2}-7.11 \log K_{\text {ow }}+10.6\right)$ 

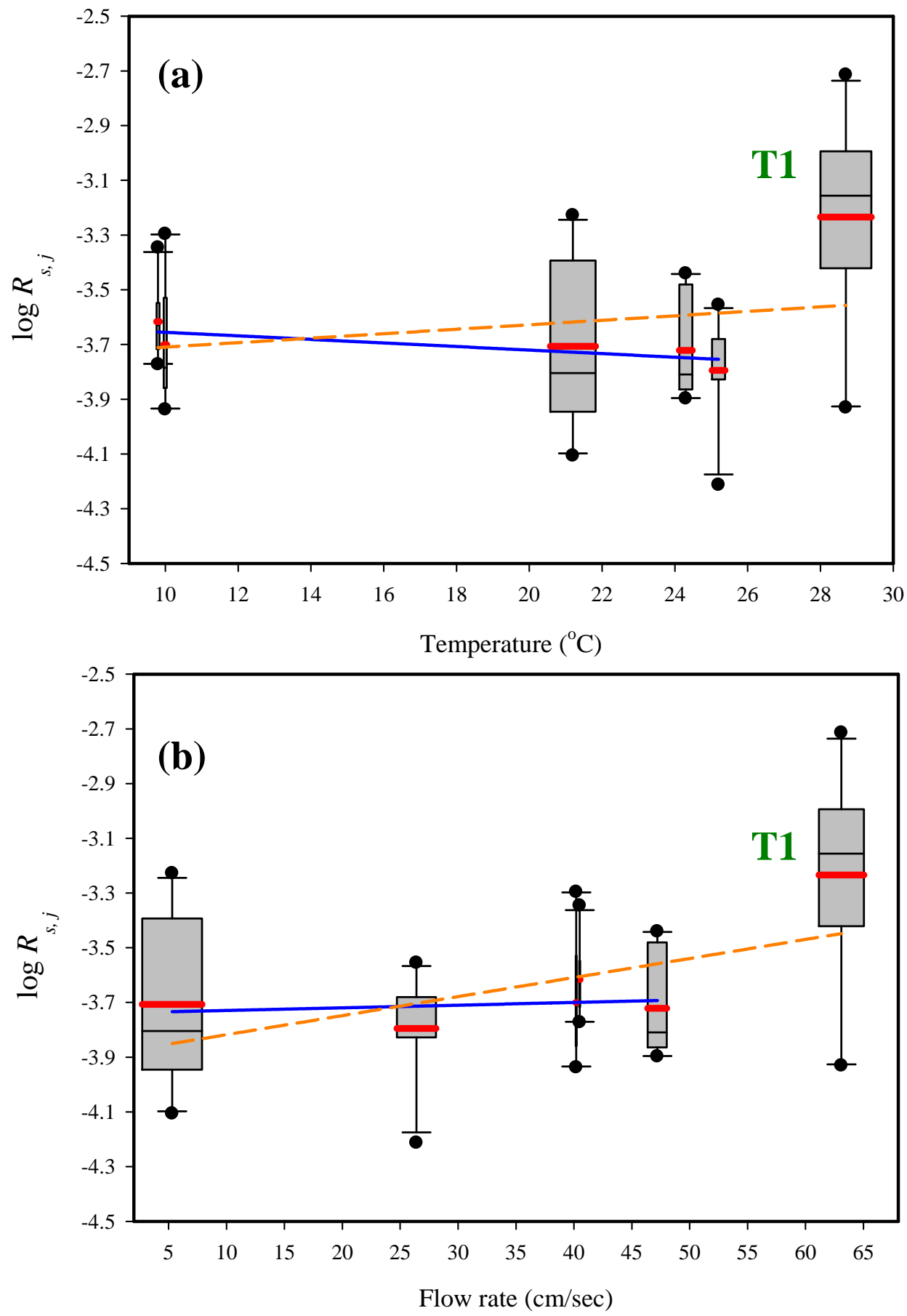

Figure $3 \log \left(R_{s, \mathrm{j}}\right)$ distribution with (a) temperatures and (b) flow rates. Bold Dashed Line: Linear regressions using $\log \left(R_{s, \mathrm{j}}\right)$ with temperatures and flow rates from all stations. Bold Solid Line: linear regressions using $\log \left(R_{s, \mathrm{j}}\right)$ with temperatures and flow rates from five stations without $\mathrm{T} 1$ station. 


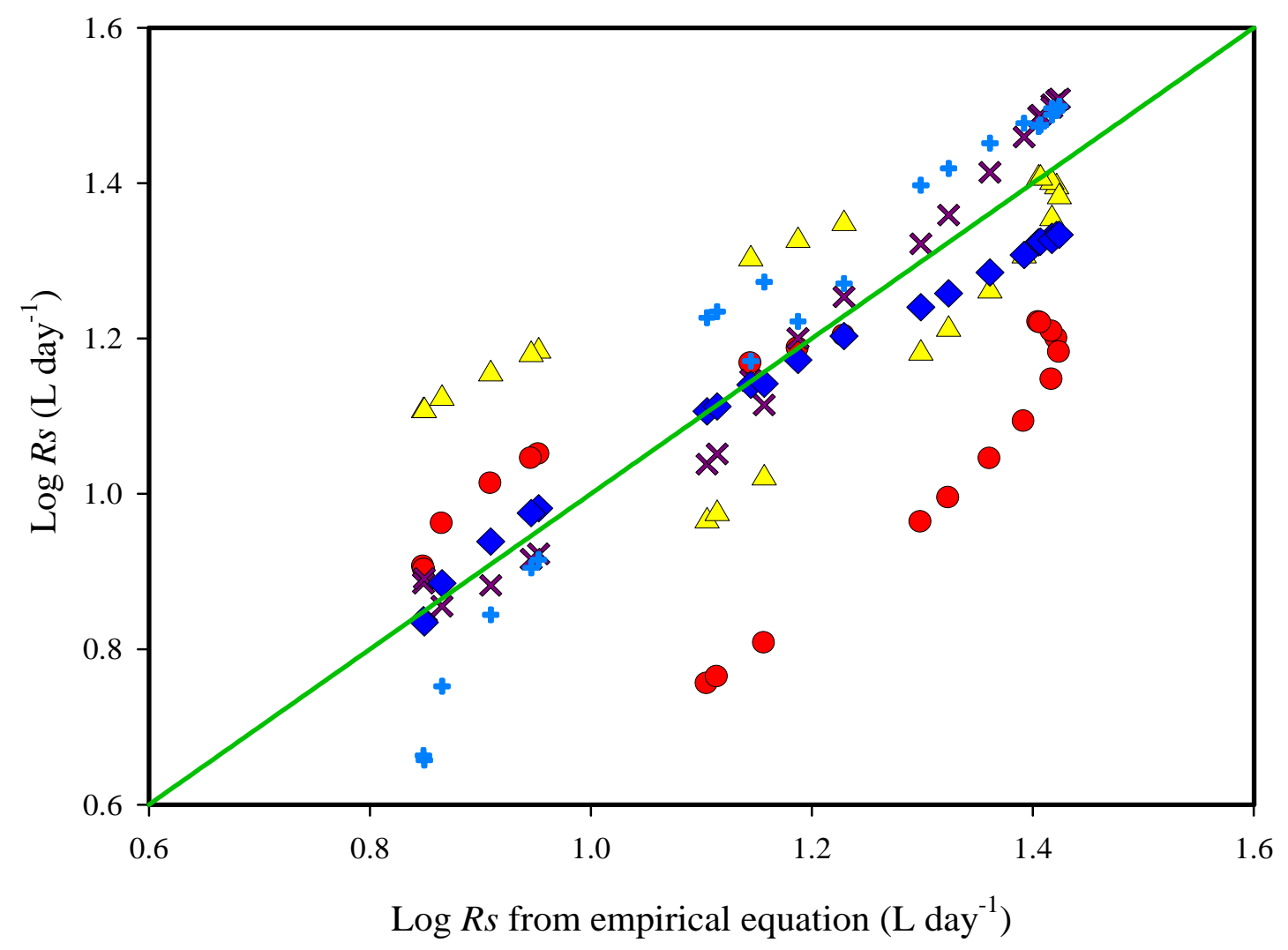

Figure $4 \log \left(R_{s}\right)$ from PRCs in this study with $\log \left(R_{s}\right)$ values from empirical equation. Circles: C1 station; Triangles: C2-A station; Crosses: C2-B station; Diamonds: T2 station; Plus Signs: T3 station. 


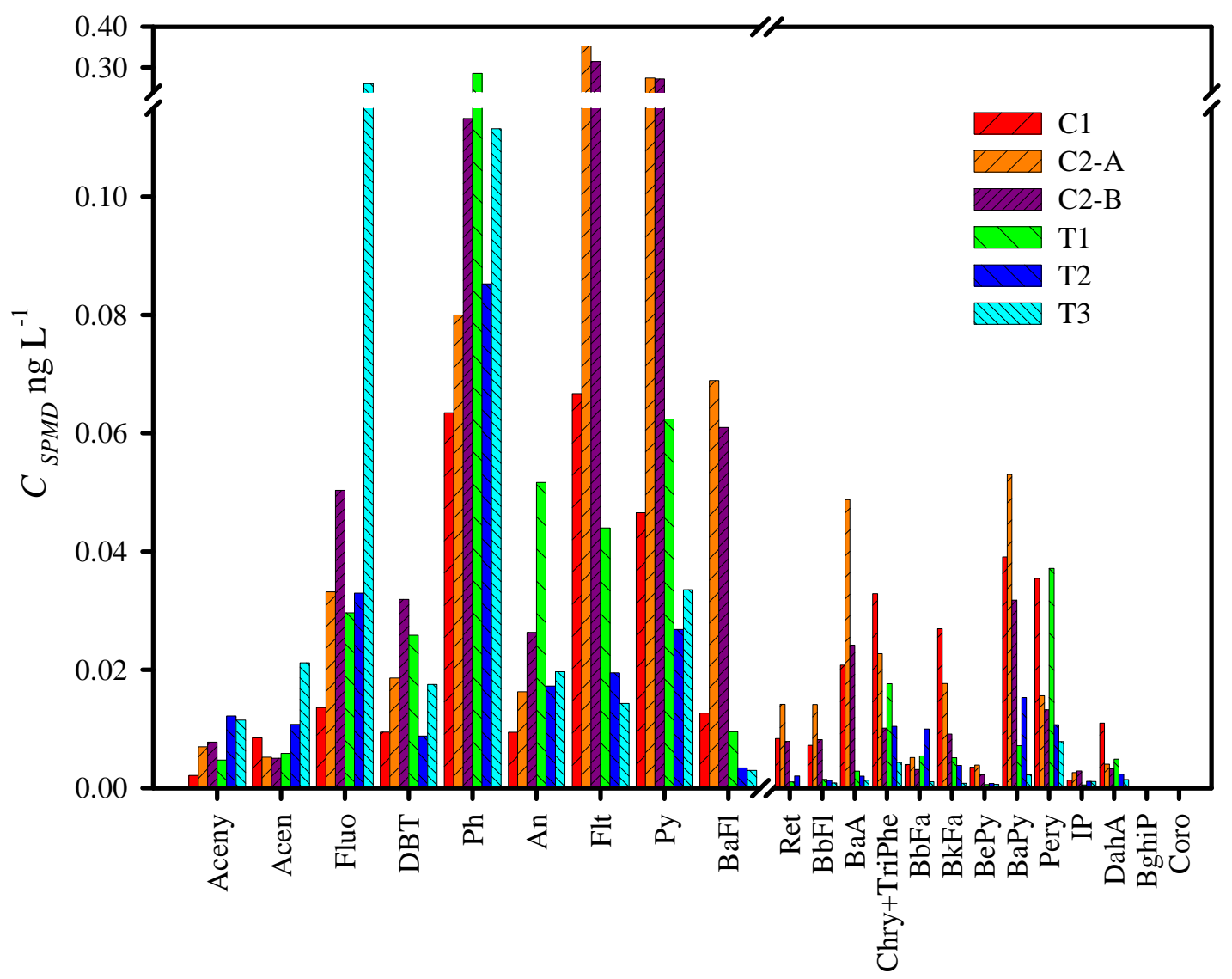

Figure 5 Bioavailable PAH concentrations from SPMDs ( $\left.C_{\text {SPMD }}\right)$. 


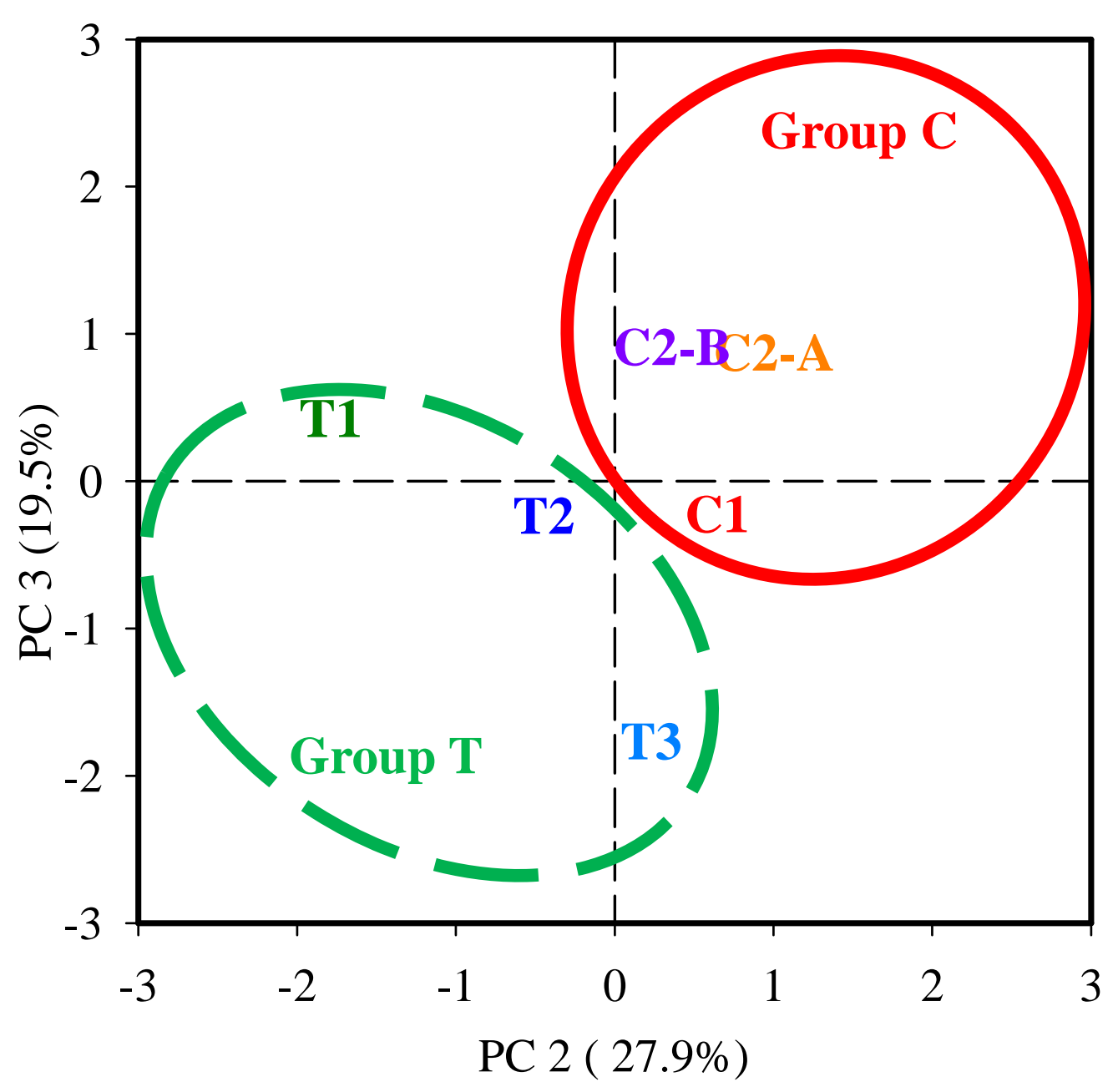

Figure 6 Scores plot of the two principal components (PC2and PC3) from the Taiwan Strait. Dashed Line encloses the group on the eastern side of the Taiwan Strait; Solid Line encloses the group on the western side of the Taiwan Strait. 
Table $1 N / N_{0}, k_{e-\mathrm{PRC}}, R_{s}$ and $B_{w}$ for SPMDs from sampling sites

\begin{tabular}{|c|c|c|c|c|c|c|}
\hline \multirow{2}{*}{$\begin{array}{l}\text { Compounds } \\
\log K_{s w} \\
\end{array}$} & & \multirow{2}{*}{$\begin{array}{c}\text { Acen-d10 } \\
4.00 \\
\end{array}$} & \multirow{2}{*}{$\begin{array}{c}\text { An-d10 } \\
4.56 \\
\end{array}$} & \multirow{2}{*}{$\begin{array}{c}\text { Py-d10 } \\
4.95 \\
\end{array}$} & \multirow{2}{*}{$\begin{array}{c}\text { BkFa-d12 } \\
5.53 \\
\end{array}$} & \multirow{2}{*}{$\begin{array}{c}\text { INP-d12 } \\
5.69 \\
\end{array}$} \\
\hline & & & & & & \\
\hline \multirow[t]{12}{*}{$N / N_{n}(\%)$} & C1-1 & 5.25 & 27.2 & 58.0 & 80.2 & 97.6 \\
\hline & $\mathrm{C} 1-2$ & 4.61 & 19.4 & 57.5 & 86.8 & 91.9 \\
\hline & $\mathrm{C} 2-\mathrm{A} 1$ & 0.08 & 4.04 & 38.5 & 69.7 & 90.6 \\
\hline & $\mathrm{C} 2-\mathrm{A} 2$ & 0.11 & 4.03 & 34.5 & 59.0 & 89.0 \\
\hline & C2-B1 & 2.48 & 26.0 & 46.2 & 55.3 & 86.3 \\
\hline & $\mathrm{C} 2-\mathrm{B} 2$ & 0.59 & 16.4 & 44.6 & 56.8 & 89.3 \\
\hline & $\mathrm{T} 1-1$ & 9.80 & 39.5 & 69.6 & 88.9 & 96.7 \\
\hline & $\mathrm{T} 1-2$ & 7.17 & 35.3 & 71.3 & 79.0 & 93.1 \\
\hline & $\mathrm{T} 2-1$ & 5.94 & 29.4 & 58.2 & 74.4 & 92.5 \\
\hline & $\mathrm{T} 2-2$ & 6.61 & 29.0 & 56.2 & 75.8 & 85.7 \\
\hline & T3-1 & 8.67 & 24.6 & 48.6 & 66.0 & 86.4 \\
\hline & $\mathrm{T} 3-2$ & 13.4 & 29.5 & 47.4 & 54.8 & 81.4 \\
\hline \multirow{12}{*}{$k_{e \cdot \operatorname{PRC}}\left(\mathrm{d}^{-1}\right)$} & C1-1 & 0.151 & 0.067 & 0.028 & 0.011 & 0.001 \\
\hline & C1-2 & 0.158 & 0.084 & 0.028 & 0.007 & 0.004 \\
\hline & $\mathrm{C} 2-\mathrm{A} 1$ & 0.247 & 0.112 & 0.033 & 0.013 & 0.003 \\
\hline & $\mathrm{C} 2-\mathrm{A} 2$ & 0.236 & 0.112 & 0.037 & 0.018 & 0.004 \\
\hline & $\mathrm{C} 2-\mathrm{B} 1$ & 0.129 & 0.047 & 0.027 & 0.021 & 0.005 \\
\hline & $\mathrm{C} 2-\mathrm{B} 2$ & 0.179 & 0.063 & 0.028 & 0.020 & 0.004 \\
\hline & $\mathrm{T} 1-1$ & 0.774 & 0.048 & 0.121 & 0.039 & 0.011 \\
\hline & $\mathrm{T} 1-2$ & 0.878 & 0.053 & 0.113 & 0.079 & 0.024 \\
\hline & $\mathrm{T} 2-1$ & 0.135 & 0.063 & 0.026 & 0.014 & 0.004 \\
\hline & $\mathrm{T} 2-2$ & 0.130 & 0.063 & 0.028 & 0.013 & 0.007 \\
\hline & T3-1 & 0.085 & 0.049 & 0.025 & 0.014 & 0.005 \\
\hline & $\mathrm{T} 3-2$ & 0.070 & 0.042 & 0.026 & 0.021 & 0.007 \\
\hline \multirow[t]{12}{*}{$R_{s-\mathrm{PRC}}\left(\mathrm{Ld} \mathrm{d}^{-1}\right)$} & C1-1 & 7.44 & 11.8 & 12.2 & 18.9 & 2.97 \\
\hline & C1-2 & 7.77 & 14.9 & 12.4 & 12.1 & 10.4 \\
\hline & $\mathrm{C} 2-\mathrm{A} 1$ & 12.2 & 19.8 & 14.5 & 20.9 & 8.18 \\
\hline & $\mathrm{C} 2-\mathrm{A} 2$ & 11.6 & 19.8 & 16.2 & 30.5 & 9.62 \\
\hline & C2-B1 & 6.33 & 8.31 & 11.7 & 34.3 & 12.2 \\
\hline & $\mathrm{C} 2-\mathrm{B} 2$ & 8.79 & 11.1 & 12.3 & 32.8 & 9.38 \\
\hline & T1-1 & 38.1 & 8.44 & 52.8 & 65.5 & 26.2 \\
\hline & $\mathrm{T} 1-2$ & 43.2 & 9.45 & 49.1 & 131 & 56.6 \\
\hline & $\mathrm{T} 2-1$ & 6.65 & 11.1 & 11.3 & 23.5 & 8.84 \\
\hline & $\mathrm{T} 2-2$ & 6.40 & 11.2 & 12.0 & 22.0 & 17.6 \\
\hline & T3-1 & 4.82 & 9.95 & 12.6 & 27.7 & 13.9 \\
\hline & T3-2 & 3.96 & 8.64 & 13.1 & 40.0 & 19.5 \\
\hline \multirow[t]{10}{*}{$\log R_{s, \mathrm{i}}$} & C1-1 & -3.83 & -3.78 & -3.83 & -3.56 & -4.21 \\
\hline & C1-2 & -3.81 & -3.68 & -3.82 & -3.75 & -3.67 \\
\hline & $\mathrm{C} 2-\mathrm{A} 1$ & -3.62 & -3.56 & -3.75 & -3.51 & -3.77 \\
\hline & $\mathrm{C} 2-\mathrm{A} 2$ & -3.64 & -3.56 & -3.70 & -3.35 & -3.70 \\
\hline & C2-B1 & -3.90 & -3.94 & -3.84 & -3.30 & -3.60 \\
\hline & $\mathrm{C} 2-\mathrm{B} 2$ & -3.76 & -3.81 & -3.82 & -3.31 & -3.71 \\
\hline & $\mathrm{T} 1-1$ & -3.12 & -3.93 & -3.19 & -3.01 & -3.27 \\
\hline & T1-2 & -3.07 & -3.88 & -3.22 & -2.71 & -2.93 \\
\hline & T2-1 & -3.88 & -3.81 & -3.86 & -3.46 & -3.74 \\
\hline & $\mathrm{T} 2-2$ & -3.90 & -3.81 & -3.83 & -3.49 & -3.44 \\
\hline
\end{tabular}




\begin{tabular}{llllll} 
T3-1 & -4.02 & -3.86 & -3.81 & -3.39 & -3.54 \\
T3-2 & -4.11 & -3.92 & -3.80 & -3.23 & -3.39 \\
\hline
\end{tabular}

Table 2 The root mean squared error (RMSE) and mean of absolute error (MAE) for $\log \left(R_{S}\right)$ values calculated from empirical equation with $\log \left(R_{S}\right)$ values.

\begin{tabular}{lcc}
\hline & RMSE & MAE \\
\hline C1 & 0.225 & 0.191 \\
C2-A & 0.156 & 0.131 \\
C2-B & 0.055 & 0.048 \\
T2 & 0.056 & 0.045 \\
T3 & 0.096 & 0.086 \\
\hline
\end{tabular}


Table 3 Rotated component loadings of PAHs in Taiwan Strait. Values in bold indicated those with an absolute value greater than 0.65 factors corresponding to correlation matrix eigenvalues of $>1$ are considered meaningful.

\begin{tabular}{|c|c|c|c|c|}
\hline Total variance & PC1 & PC2 & PC3 & PC4 \\
\hline explained & 38.5 & 27.9 & 19.5 & 12.9 \\
\hline Aceny & -.193 & -.210 & -.451 & .844 \\
\hline Acen & .005 & -.070 & -.884 & .462 \\
\hline Fluo & -.431 & .048 & -.894 & -.115 \\
\hline DBT & -.256 & -.882 & -.212 & -.098 \\
\hline $\mathrm{Ph}$ & .082 & -.977 & -.154 & .042 \\
\hline An & -.017 & -.982 & -.093 & .144 \\
\hline Flt & -.167 & .597 & .774 & -.121 \\
\hline Py & -.350 & .478 & .794 & -.087 \\
\hline $\mathrm{BaFl}$ & -.178 & .579 & .779 & -.153 \\
\hline Ret & .686 & .624 & .358 & .091 \\
\hline $\mathrm{BbFl}$ & .600 & .683 & .402 & -.079 \\
\hline $\mathrm{BaA}$ & .483 & .718 & .451 & -.169 \\
\hline Chry & .990 & .065 & -.002 & .120 \\
\hline $\mathrm{BbFa}$ & .226 & -.308 & -.048 & .917 \\
\hline $\mathrm{BkFa}$ & .930 & .356 & .057 & -.048 \\
\hline BePy & .846 & .526 & .071 & .033 \\
\hline $\mathrm{BaPy}$ & .781 & .473 & .231 & .336 \\
\hline Pery & .934 & -.344 & -.021 & -.092 \\
\hline IP & .174 & .474 & -.052 & .832 \\
\hline DahA & .988 & .095 & -.065 & -.025 \\
\hline BghiP & .921 & -.160 & -.105 & .336 \\
\hline Coro & .991 & .000 & -.089 & .022 \\
\hline
\end{tabular}




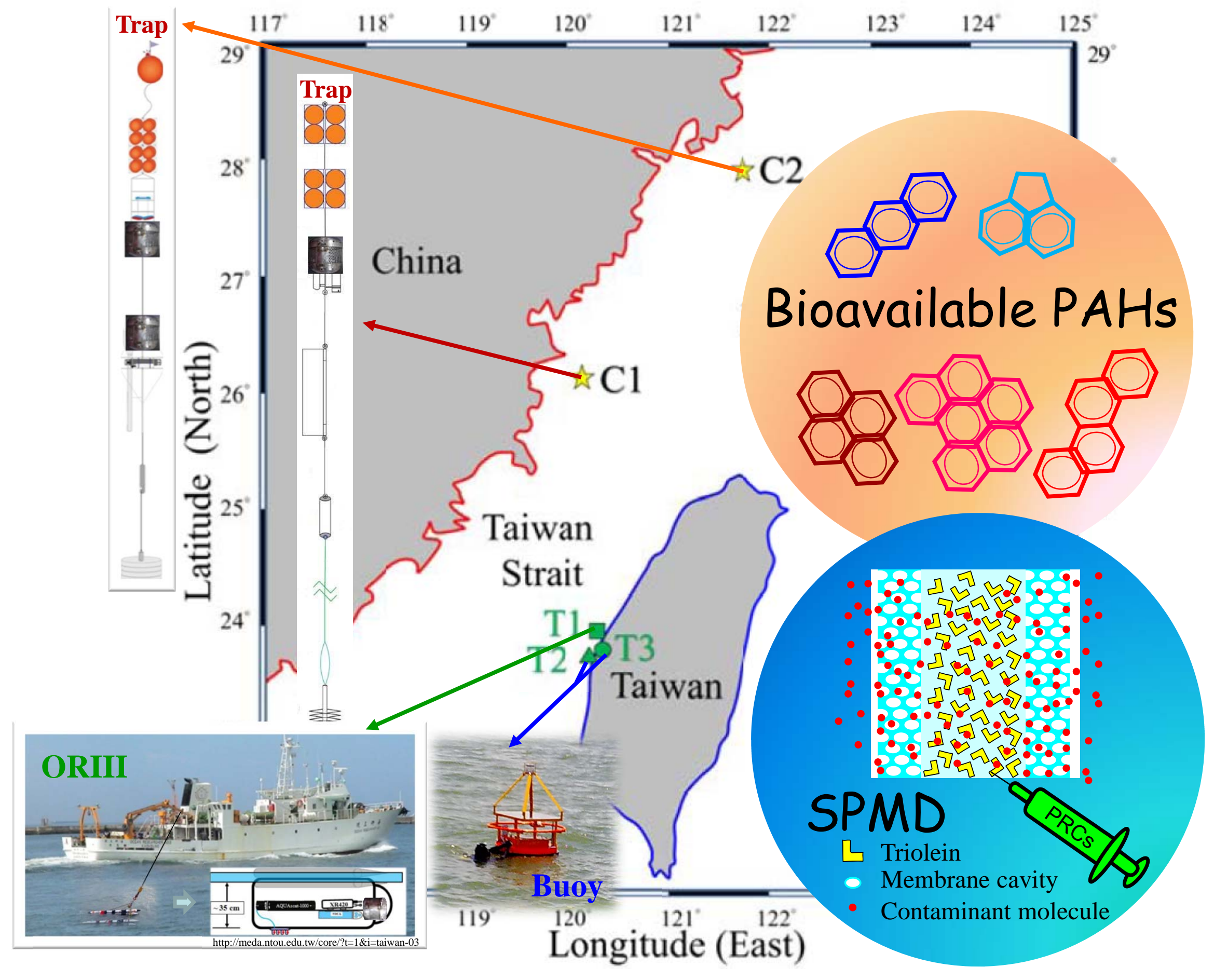

